\title{
Microstructure and Texture Changes in a Low-alloyed TRIP- aided Steel Induced by Small Plastic Deformation
}

\author{
Anna WASILKOWSKA, ${ }^{1)}$ Roumen PETROV ${ }^{2)}$ Leo KESTENS, ${ }^{2)}$ E. A. WERNER, ${ }^{1)}$ C. KREMPASZKY, ${ }^{1)}$ \\ S. TRAINT ${ }^{3)}$ and A. PICHLER ${ }^{3)}$
}

1) Christian-Doppler Laboratory for Material Mechanics of High Performance Alloys, Technical University Munich, Boltzmannstr. 15, D-85748 Garching, Germany. Technologiepark 903, 9052 Ghent, Belgium.

2) Department of Metallurgy and Materials Science, Ghent University, 3) Voestalpine Stahl Linz AG, Austria.

(Received on August 26, 2005; accepted on November 4, 2005)

\begin{abstract}
The microstructures and the textures of TRIP-assisted and Dual Phase steel in undeformed state and after $10 \%$ strain applied parallel to the rolling direction of the steel sheet were studied by optical microscopy, EBSD, TEM and XRD.

It was found that the strain-induced transformation of retained austenite to martensite leads to localized deformation of ferrite close to the ferrite/martensite phase boundaries and the formation of a composite skeleton of several phases (bainite, retained austenite and martensite), clasping the ferrite grains, which thereby decrease in size. Ferrite and retained austenite deform simultaneously to minimize the local stresses at the phase boundaries, until the strain-induced martensitic transformation takes place. The compositelike strengthening behaviour in a TRIP-aided steel might be expressed by the decreasing free path of dislocations in ferrite due to the enlarging and thickening of the multiphase skeleton as plastic deformation progresses, without changing significantly the main texture components in the material.
\end{abstract}

KEY WORDS: microstructure; microtexture; TRIP-aided steel; plastic deformation; EBSD; martensite transformation.

\section{Introduction}

Low-carbon low-alloyed TRIP-aided steels with a typical composition of $\mathrm{Fe}-0.15 \% \mathrm{C}-1.5 \% \mathrm{Si}-1.5 \% \mathrm{Mn}$ are produced as thin sheets with enhanced strength and formability. ${ }^{1)}$ Their fine grained and heterogeneous microstructure consists of ferrite and 10 to $15 \mathrm{vol} \%$ of retained austenite. During sheet forming, the strain-induced martensitic transformation (SIMT) of retained austenite can take place. The decreasing content of retained austenite during plastic straining can be followed experimentally by magnetic saturation measurements. Optimum transformation kinetics ensures a continuous increase of the instantaneous strainhardening exponent, and thus an enhancement of the uniform elongation of the material. ${ }^{2)}$ The advantages of TRIPsteels over ferrite-martensite (DP: dual-phase) steels stem from an increasing content of dispersed martensite during straining of the TRIP steel leading to a progressive strengthening of the ferritic matrix, and from an increased cumulative uniform elongation as a result of the additional plastic deformation caused by the volume expansion of the transforming grains.

Tensile tests showed that multiphase fine-grained TRIPaided sheets exhibit fairly isotropic mechanical properties with $r$-values of about 1 . An orientation dependence of the tensile properties can be induced by pre-straining of the sheets ${ }^{3)}$ which is basically associated with development of dislocation substructure and deformation texture Recently, the texture evolution was studied of a TRIP700 sheet after sequential tensile testing up to $20 \%$ of effective strain. ${ }^{4)}$ It is expected for TRIP-aided steels that by activating only some of the 24 possible crystallographic variants (martensite variant selection), ${ }^{5-7)}$ an optimized adjustment of the microstructure to local stress and strain heterogeneities during sheet forming may be possible. However, these studies have not revealed how the partial martensite transformation of the retained austenite during pre-straining contributes to the deformation texture of the ferrite matrix.

For this purpose, in the present studies a dual-phase ferrite-martensite steel DP600 with constant volume content of martensite, developing a texture without the contribution of SIMT, is used as a reference alloy. The uniaxial tensile tests were complemented by X-ray and EBSD-measurements of the texture evolution in these high-strength thin sheet steels.

\section{Experimental}

\subsection{Materials}

The compositions and the thickness of the low-alloyed TRIP and the dual-phase steels investigated in this work are given in Table 1. After cold-rolling, both steels were heat treated in order to obtain the desired microstructures consisting of ferrite, bainite and retained austenite (TRIP-aided steel) or ferrite and martensite (dual phase steel). The heat treatment of the TRIP steel consisted of reheating to $800^{\circ} \mathrm{C}$ 
Table 1. Thickness and chemical composition (in mass $\%$ ) of the steel sheets investigated.

\begin{tabular}{|c|c|c|c|c|c|c|c|c|c|c|}
\hline Sheet & Thickness, $\mathrm{mm}$ & $\mathrm{C}$ & $\mathrm{Mn}$ & $\mathrm{Si}$ & $\mathrm{Cr}$ & $\mathrm{P}$ & $\mathrm{S}$ & $\mathrm{Cu}$ & $\mathrm{Ni}$ & $\mathrm{Mo}$ \\
\hline TRIP & 1.27 & 0.2 & 1.5 & 1.5 & 0.03 & 0.01 & 0.0007 & 0.074 & 0.020 & 0.005 \\
\hline DP600 & 1.47 & 0.1 & 1.5 & 0.1 & 0.77 & 0.01 & 0.0054 & 0.061 & 0.024 & 0.003 \\
\hline
\end{tabular}

for $60 \mathrm{~s}$ followed by annealing at $400^{\circ} \mathrm{C}$ in the bainitic region. The dual phase steel was subjected to a heat treatment comprising intercritical annealing at $810^{\circ} \mathrm{C}$ followed by controlled quenching to room temperature.

\subsection{Mechanical Tests and Microstructure Characteri- zation}

Standard size A50 tensile test samples (DIN 50114) with a gauge length of $50 \mathrm{~mm}$ and a width of $12,5 \mathrm{~mm}$ were cut parallel to the rolling direction (RD) of the sheet and were deformed to $10 \%$ of plastic strain at initial strain rate of $4 \times 10^{-3} \mathrm{~s}^{-1}$. The microstructure, the amount of retained austenite and the mechanical properties of the strips before and after pre-straining were studied in order to evaluate the influence of the pre-strain on the mechanical and transformation behaviour (if applicable) of the materials.

The microstructure of the steels was characterized by means of light optical microscopy after mechanical polishing and colour etching ${ }^{8)}$ and by means of the EBSD technique after mechanical polishing (final step: $0.035 \mu \mathrm{m}$ colloidal silica). All observations were carried out in the rolling plane (the plane which is perpendicular to the normal direction (ND) of the sheet). The EBSD system was attached to a FEI Environmental Scanning Electron Microscope (ESEM XL30) with an $\mathrm{LaB}_{6}$ filament. The EBSD patterns were acquired under the following condition: accelerating voltage $25 \mathrm{kV}$, specimen tilt $75^{\circ}$, scan step $0.2 \mu \mathrm{m}$ and a hexagonal scanning grid. Each individual scan covers a surface of $40 \times 80 \mu \mathrm{m}^{2}$ and contains about 1200 individual grains (orientations). The EBSD data were post-processed by means of the commercial $\mathrm{TSL}^{\circledR}$ software.*

The EBSD measurements were carried out in the middle thickness section of the samples in a plane perpendicular to the normal direction of the strip before and after the prestraining. Adjacent points were assumed to belong to the same grain, if their misorientation-angle was lower than $5^{\circ}$. The minimum grain size was chosen to be 2 measuring points, which were $0.2 \mu \mathrm{m}$ apart. These parameters are commonly used in this type of analysis. ${ }^{9)}$ All data points with a confidence index (CI) lower than 0.1 were excluded from the analysis as dubious points. The CI quantifies the reliability of the indexed pattern. The automatic crystal orientation mapping in the scanning electron microscope allows discrimination between ferrite and retained austenite which is based on the differences in their crystal structure. The distribution of the image quality factor (IQ), which corresponds to the contrast of the detected Kikuchi pattern, was used to separate bainite from primary ferrite in the bcc phase. At a lower level of strain, average misorientation calculations between neighbouring data points were used for differentiating undeformed from deformed ferrite zones. ${ }^{10)}$

The grain size of ferrite and retained austenite was deter- mined by image analysis from metallographic sections (linear intercept method) and by means of EBSD data, postprocessed by the TSL ${ }^{\circledR}$ software. Part of the deformed specimens was prepared for transmission electron microscopy. The thin foils were double-jet polished in A8 -Struers electrolyte using Tenupol facilities. The amount of retained austenite was measured by means of magnetic saturation measurements as a function of the plastic strain. ${ }^{11)}$ The results were compared to the once obtained by means of EBSD.

\subsection{Texture Analysis}

The bulk texture of the strips was measured by means of the X-ray diffractometer Bruker A8- Advance and filtered Co- $\mathrm{K}_{\alpha}$-radiation. The texture is characterized by means of pole figures representing the $\{\mathrm{hkl}\}$ planes of grains parallel to the rolling plane of the sheet and the $\langle u v w\rangle$ directions parallel to the rolling direction. The frequency of occurrence of particular orientations is characterized by the orientation distribution function (ODF) in 3D orientation space. This space is defined by the Euler angles $\varphi_{1}, \Phi$ and $\varphi_{2}$ (in a range varying from $0^{\circ}$ to $90^{\circ}$ ), which characterize a set of three consecutive rotations that must be applied to an individual crystallite in order to bring its crystallographic $\langle 100\rangle$ axes into coincidence with the specimen axes. ${ }^{12)}$ The ODFs were calculated from the numerical data obtained from three pole figures, i.e. $\{110\},\{200\}$ and $\{211\}$ for ferrite and $\{111\},\{200\}$ and $\{220\}$ for austenite. For the calculations commercial software was used which is part of the package controlling the diffractometer. Its mathematical base is Bunge's formalism. ${ }^{13)}$ Cubic crystal symmetry and orthorhombic specimen symmetry were assumed.

In addition, the microtexture of the strips was measured by means of the EBSD technique, which allows to study easily the texture changes associated to the deformation and their distribution among the different microstructural constituents. For better statistical representation the orientation data of several individual measurements were merged and post-processed by means of the MTM-FHM software developed by Van Houtte. ${ }^{14)}$

\section{Results and Discussion}

\subsection{Microstructure and Mechanical Behaviour}

The microstructure of the investigated steels is shown in Fig. 1. In the TRIP-aided steel, the mean grain size of ferrite varies from 11 to $7 \mu \mathrm{m}$ (horizontal and vertical line sections, respectively), whereas the average austenite grain size is $\sim 1 \mu \mathrm{m}$ (Fig. 1(a)). The amount of the retained austenite determined by magnetic measurement is about 14 vol\%. The steel DP600 displays an approximately double ferrite grain size and contains about 7 vol\% martensite (Fig. 1(b)).

The presence of a hard second phase in the microstructure leads to a significant strain-hardening of the material, which can be observed already at small strains (Fig. 2). The typical difference in the flow behaviour of DP steels and TRIP-aided steels treats generally at higher strains. ${ }^{15)}$ Above $10 \%$ of plastic strain, the instantaneous strain-hard-

\footnotetext{
* TSL OIM is a trade mark of TexSem Laboratories INC., Draper, UT, USA.
} 


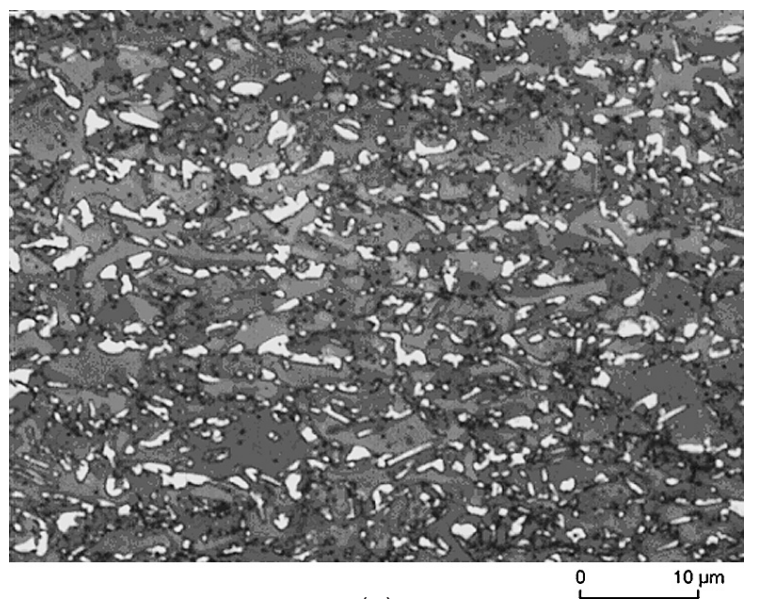

(a)

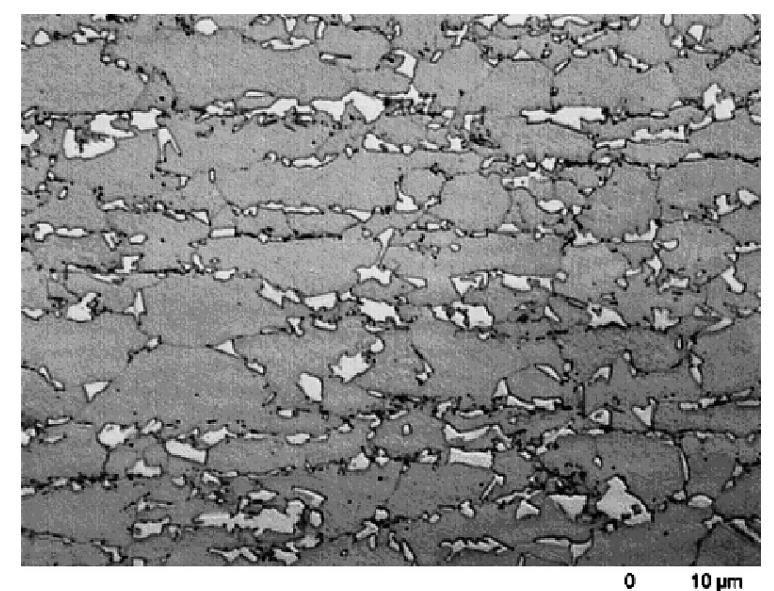

(b)

Fig. 1. Metallographic sections of the steels. (a) TRIP-aided steel with ferrite matrix and about $14 \mathrm{vol} \%$ of retained austenite (white); (b) DP600 steel with ferrite matrix and about $7 \mathrm{vol} \%$ of martensite (white).

(a)

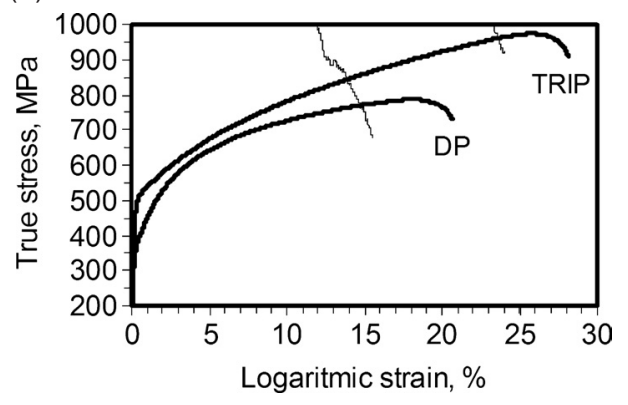

(b)

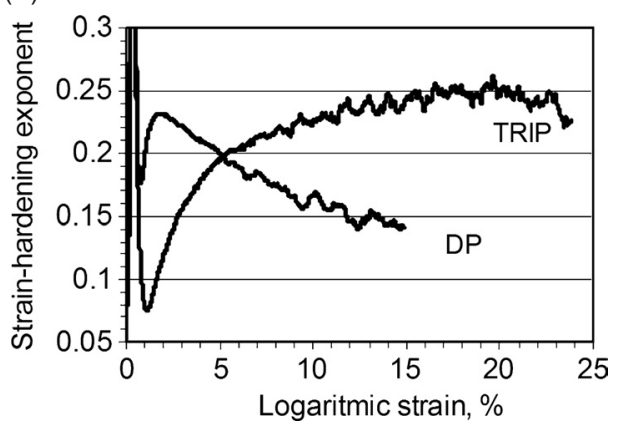

Fig. 2. Tensile behaviour of the investigated steels. (a) Stressstrain diagram of the TRIP and DP steels; (b) Strain hardening exponent $n=d \ln \sigma / d \ln \varepsilon$ as a function of strain for both steels.

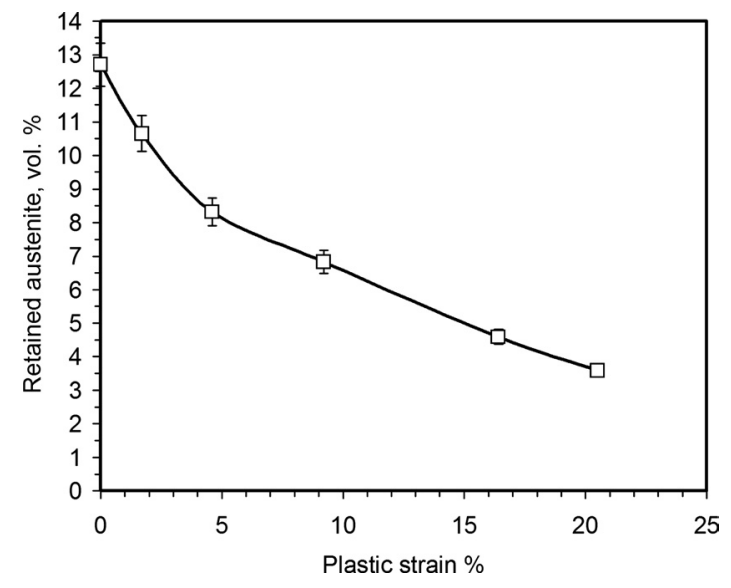

Fig. 3. Content of retained austenite as a function of plastic strain.

ening exponent is still increasing for a TRIP-aided steel and shows distinctly higher values, leading to much higher uniform elongation as compared to the ferrite-martensite steel. This complex effect (known as transformation induced plasticity, TRIP) is attributed to the continuous growth of the martensite volume content with plastic strain. The volume content of retained austenite decreases approximately in a half when straining up to $10 \%$ uniform strain (Fig. 3).

Figure 4 shows a magnified view $\left(15 \times 15 \mu \mathrm{m}^{2}\right)$ obtained by EBSD of the undeformed TRIP-aided steel. In the grey scale image quality map (Fig. 4(a)) ferrite is light grey whereas retained austenite, bainite and the grain boundaries are represented by different levels of the dark grey because their pattern contrast is less than that of ferrite. The colour coded phase map of the same zone is shown in Figs. 4(b), 4(c). The blue colour is used to delineate ferrite, retained austenite is yellow and bainite is in red. Ferrite and retained austenite were distinguished on the basis of the differences in their crystal structure, whereas for the discrimination of bainite from ferrite the differences in the image quality of the EBSD patterns were used. The bainite in this measurement is represented by an IQ-factor between 100 and 150 (Fig. 4(d)). A lower IQ-factor, between 0 and 100, corresponds to the high angle grain boundaries in the structure. Based on these measurements, an amount of $10 \%$ retained austenite is determined in the TRIP-aided steel before deformation and the remaining $90 \%$ are distributed between primary ferrite and bainite in a ratio of $3: 1$, respectively. It should be mentioned that the quantification of retained austenite and bainite by means of the EBSD measurement is heavily dependent on the magnification, i.e. at very high magnifications the amount of the phases can differ significantly from the average value determined by XRD or magnetic measurements, because of the local heterogeneities in the microstructure.

The same approach is used to quantify the microstructure of the TRIP-aided steel after $10 \%$ of tensile strain applied parallel to the rolling direction. The amount of retained austenite decreases from 10 to $4.5 \%$ and the microstructure of the bcc phase changes displaying a decrease of the IQfactor in the vicinity of the high angle grain and phase boundaries. The results of the retained austenite measurements obtained by EBSD are in good correlation with the results of the magnetic measurements which quantify the 

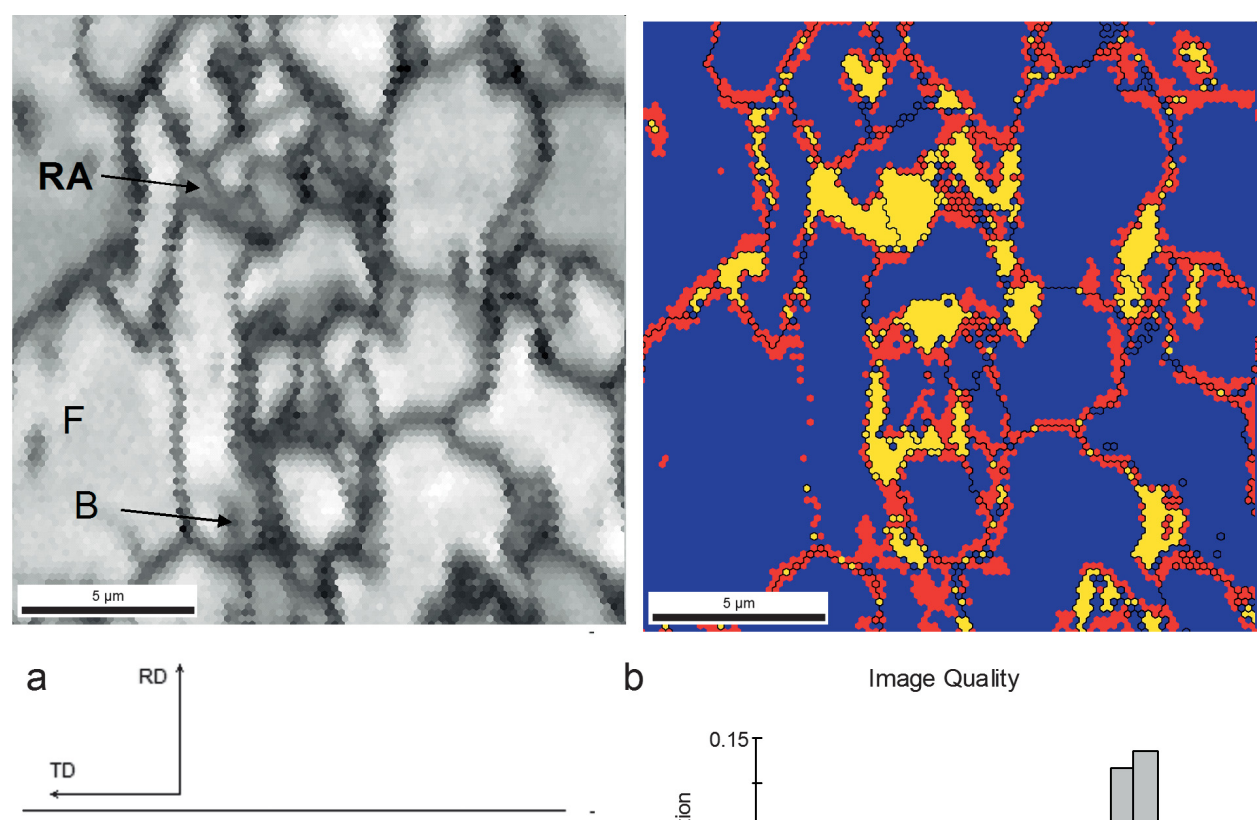

b

Image Quality

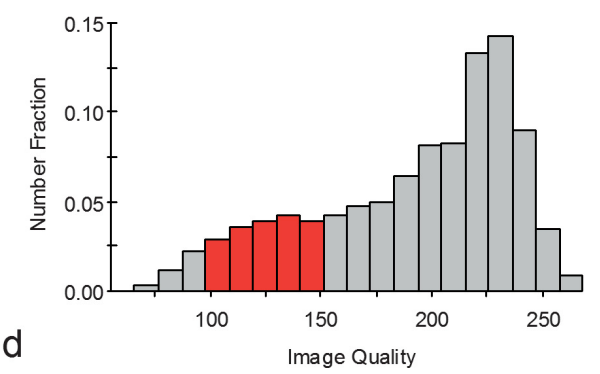

Fig. 4. Microstructure of undeformed TRIP-aided steel; (a) Image quality map: (b) Color coded phase map of the same zone (ferrite-blue, retained austenite-yellow, bainite-red); (c) code for the colors; (d) image quality chart, which was used to delineate bainite $(150>\mathrm{IQ}>100)$.
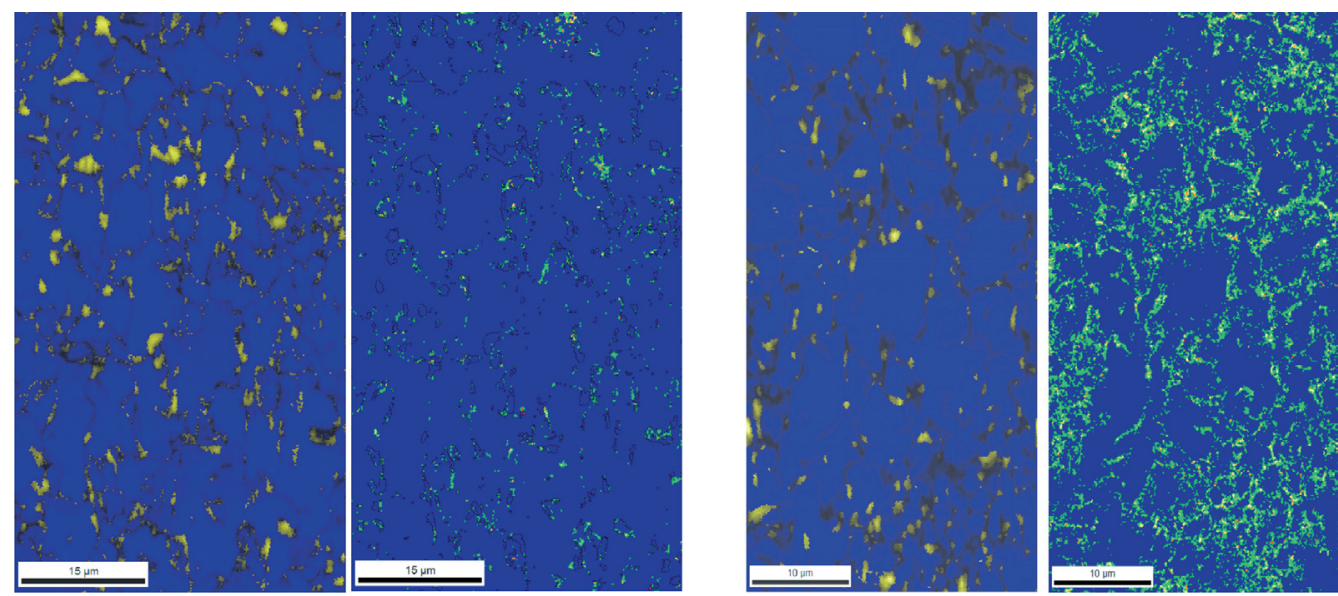

a

b

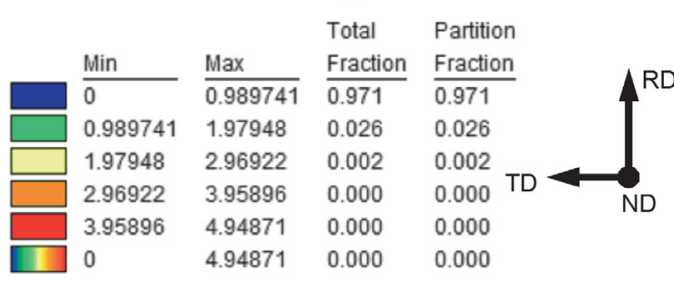

BCC (Ferrite + Bainite)

FCC (ret. Austenite)

e

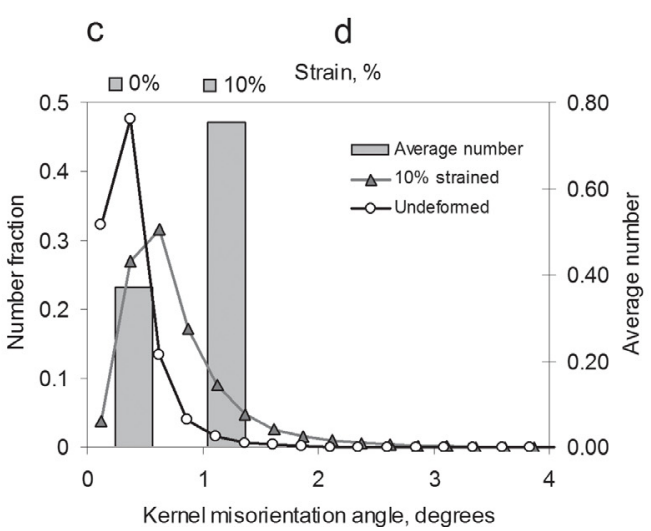

Fig. 5. Color coded phase maps of undeformed (a) and $10 \%$ plastically strained TRIP-aided steel (c); Color coded kernel average misorientation maps for undeformed (b) and 10\% plastically strained TRIP steel (d); (e) color code key for the maps and (f) Chart displaying the number fraction of the pixels with different kernel average misorientation in both samples. 
changes in the retained austenite from 12.8 vol\% before deformation to $6 \mathrm{vol} \%$ for samples after deforming to $14 \%$ strain (Fig. 3). However, a direct comparison of the amount of retained austenite measured by both methods should be done with great care, because the magnetic measurement gives an integral estimate of the quantity of the retained austenite, whereas the automatic crystal orientation mapping determines the same value on a local scale and, therefore, is very much dependent on the magnification and on the spatial resolution of the microscope.

The study of the microstructural changes in the TRIP steel after deformation show that the strain is localized in the vicinity of the $\alpha-\gamma$ phase boundaries (Fig. 5). These images show the colour coded phase maps of the TRIP steel before (Fig. 5(a)) and after (Fig. 5(c)) 10\% tensile strain applied parallel to the RD together with average misorientation colour coded maps of the undeformed and strained samples. The average misorientation map is used to evaluate the localized plastic strain in the material. According to this approach for a given kernel point the average misorientation of that point with all of its neighbours is calculated under the condition that misorientations exceeding some tolerance value are excluded from the averaging calculation. The magnitude of the kernel average misorientation is affected by the scan step size. To overcome this ambiguity, the user may select nearest, next-nearest or next-next-nearest neighbors to define the kernel. The color coded maps in Figs. 5(b) and 5(d) are calculated on the base of the first neighbours (the kernel belongs to the ferrite grains) and a maximum misorientation angle of $5^{\circ}$. The blue color in the maps displays a kernel average misorientation that varies between $0^{\circ}$ and $1^{\circ}$ and the points with red color belong to pixels that are $3^{\circ}$ to $5^{\circ}$ disoriented with respect to the kernel (i.e. the middle of the ferrite grains). The results presented in Fig. 5(d) reveal clearly the localization of the plastic strain in the vicinity of the $\alpha-\gamma$ phase boundaries, bainite zones but seldom around high angle grain boundaries. The kernel average misorientation distribution is shown in Fig. 5(f). It can be seen that the frequency of data points with an average misorientation less than $5^{\circ}$ is approximately two times higher in the $10 \%$ pre-strained strip than in the undeformed one.

\subsection{Texture Changes in the bcc Constituents (Ferrite and Bainite)}

The results of XRD texture measurements are used to calculate the orientation distribution function (ODF). The Euler angles corresponding to the maximum ODF values were recalculated into Miller indices, which represent the most common crystallographic orientations of grains in the investigated steels (Table 2). The results show that the initial texture is stronger in the TRIP-aided steel, but exhibits similar components as the DP-steel. There are no significant changes in the texture of both steels before and after deformation, but it should be mentioned that after deformation the intensity of the rotated cube $\{001\}\langle 110\rangle$ and $\{h k l\}\langle 110\rangle$ in the DP 600 steel increases from 2.5 to 3.5 times that of a random texture, whereas in the TRIP-steel the intensity of these texture components remains unchanged (Fig. 6). After deformation, a local maximum is observed of the texture around the $\{111\}\langle 110\rangle$ component
Table 2. The crystallographioc orientations in ferrite.

\begin{tabular}{|c|c|c|c|}
\hline Specimen & Orientation & $\begin{array}{l}\text { Euler angles } \\
\varphi_{1} \quad \Phi \quad \varphi_{2}\end{array}$ & $\begin{array}{c}\text { ODF } \\
\text { Intensity }\end{array}$ \\
\hline \multirow{4}{*}{$\begin{array}{l}\text { TRIP-steel } \\
\text { as-received }\end{array}$} & $\{115\}\langle 110\rangle$ & $\begin{array}{lll}0 & 1645\end{array}$ & 5.0 \\
\hline & $\{556\}\langle 110\rangle$ & $0 \quad 5045$ & 3.1 \\
\hline & $\{665\}\langle 5512\rangle$ & $90 \quad 60 \quad 45$ & 3.1 \\
\hline & $\sim\{111\}\langle 112\rangle$ & $90 \quad 55 \quad 45$ & 3.1 \\
\hline \multirow{2}{*}{$\begin{array}{c}\text { TRIP-steel } \\
10 \% \text { deformed }\end{array}$} & $\{001\}\langle 110\rangle$ & $\begin{array}{lll}0 & 0 & 45\end{array}$ & 4.9 \\
\hline & $\{111\}\langle 110\rangle$ & $\begin{array}{lll}0 & 55 \quad 45\end{array}$ & 2.1 \\
\hline \multirow{4}{*}{$\begin{array}{c}\text { DP steel } \\
\text { as-received }\end{array}$} & $\{115\}\langle 110\rangle$ & $\begin{array}{lll}0 & 16 & 45\end{array}$ & 2.6 \\
\hline & $\{112\}\langle 110\rangle$ & 03545 & 2.2 \\
\hline & $\{111\}\langle 112\rangle$ & $90 \quad 55 \quad 45$ & 1.7 \\
\hline & $\{111\}\langle 110\rangle$ & $\begin{array}{lll}0 & 55 & 45\end{array}$ & 1.9 \\
\hline \multirow{5}{*}{$\begin{array}{c}\text { DP steel } \\
10 \% \text { deformed }\end{array}$} & $\{115\}\langle 110\rangle$ & $\begin{array}{lll}0 & 16 & 45\end{array}$ & 3.5 \\
\hline & $\{112\}\langle 110\rangle$ & 03545 & 2.8 \\
\hline & $\{111\}\langle 110\rangle$ & $0 \quad 55 \quad 45$ & 2.5 \\
\hline & $\{332\}\langle 110\rangle$ & $\begin{array}{lll}0 & 65 & 45\end{array}$ & 1.8 \\
\hline & $\{111\}\langle 112\rangle$ & $90 \quad 55 \quad 45$ & 1.6 \\
\hline
\end{tabular}

(a)

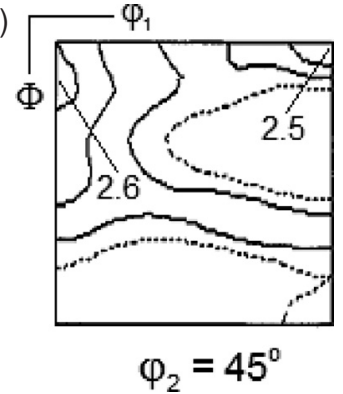

(c)

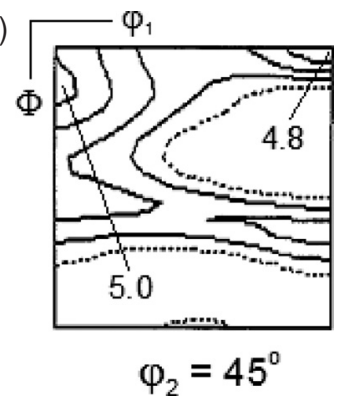

(b)

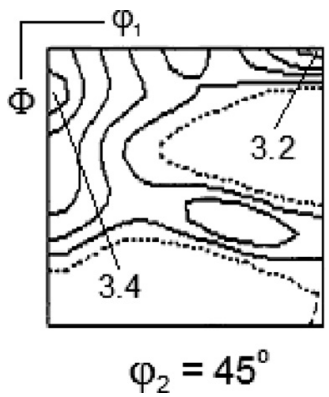

(d)

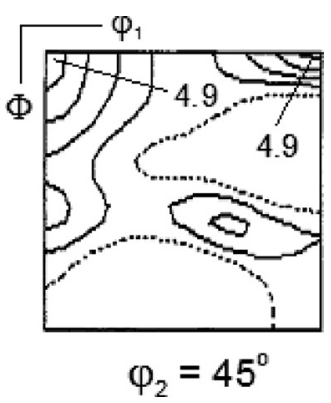

Fig. 6. ODF of ferrite in the steel DP600 (a, b), and in the TRIPaided steel (c, d), before (a) and (c) and after (b) and (d) $10 \%$ of plastic strain applied parallel to the RD of the sheet.

in both steels. This means that under the action of uni-axial tension the near equal distribution of $\{115\}$ to $\{111\}$ crystal planes parallel to the rolling plane (RP) has gradually shifted toward a preference of $\{111\}$ planes//RP. The $\{001\}\langle 110\rangle$ and $\{111\}\langle 110\rangle$ texture components become pronounced in the deformed TRIP-aided steel, which is typical for plastic deformation of a bcc-crystal by dislocation slip.

Similar results were obtained from the EBSD analysis of ferrite and bainite. The results of local texture measurements of undeformed and deformed TRIP-steel are shown in Fig. 7. The strongest ferrite texture component in the undeformed TRIP-steel is $\{112\}\langle 110\rangle$ with an intensity of 11 times that of a random texture (Fig. 7(a)) together with $\{111\}\langle 7114\rangle$ and $\{111\}\langle 145\rangle$ texture components with intensity of 10 and 8 , respectively. The undeformed bainite possesses the same main texture components as the ferrite 


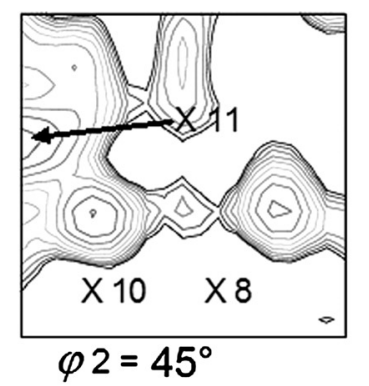

a Ferrite

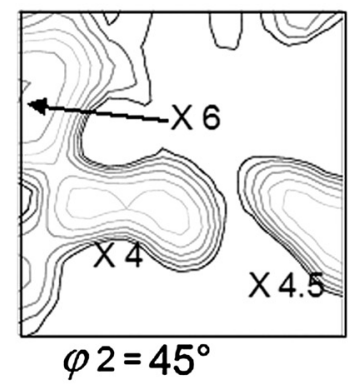

C Ferrite $10 \% \mathrm{RD}$

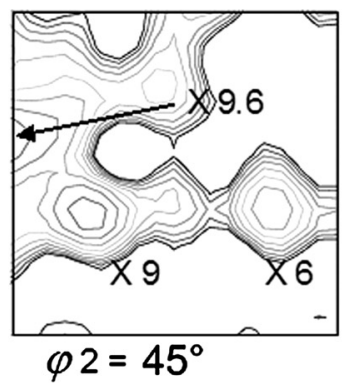

b Bainite

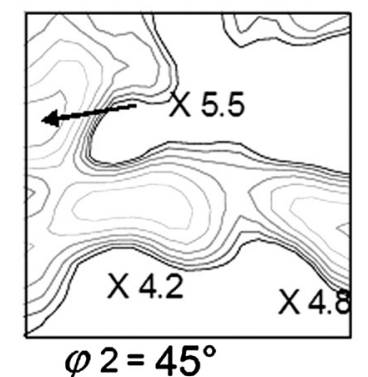

d Bainite $10 \% \mathrm{RD}$
Texture Name: Harmonic: $L=16, H W=5.0$

Calculation Method: Harmonic Series Expansion

Series Rank (1): 16

Gaussian Smoothing: $5.0^{\circ}$

Sample Symmetry: Orthotropic

Repres entation: Euler Angles (Bunge)

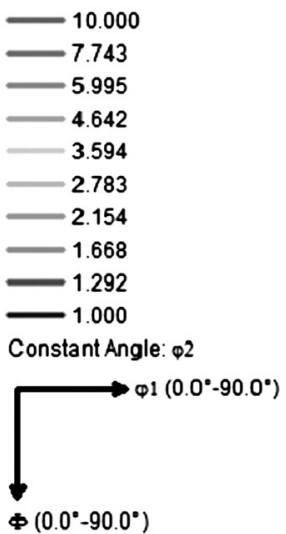

e

Fig. 7. Local textures of ferrite and bainite before (a, b) and after $10 \%$ pre-strain//RD (c, d); (e) iso-intensity levels.

but with a lower intensity (cf. Fig. 7(b)). After $10 \%$ of plastic strain the strongest texture component of the undeformed ferrite $\{112\}\langle 110\rangle$ changes to $\{114\}\langle 110\rangle$ and its intensity decreases from 11 to 6 times that of a random texture. The weaker texture component of the undeformed ferrite $\{111\}\langle 145\rangle$ rotates towards the $\{554\}\langle 225\rangle$ component. The $\{111\}\langle 7114\rangle$ texture component remains unchanged, but its intensity also decreases from 10 to 4 in ferrite and from 9 to 4.2 in bainite. After deformation, the $\{332\}\langle 110\rangle$ texture component, which was not present in the undeformed bcc-phase, is observed both in strained ferrite and bainite with an intensity of 2.8 .

\subsection{Texture Changes of Retained Austenite}

The deformation texture of retained austenite in TRIPaided steel was determined by XRD (Table 3) and the discrete EBSD techniques (Fig. 8). The ODF of the retained austenite in the undeformed TRIP steel contains a strong Brass $(\{110\}\langle 112\rangle)$ texture component with an intensity of 6.3 and a weaker $\operatorname{Goss}(\{110\}\langle 001\rangle)$ component with an intensity of 2 (Figs. 8(a), (b)). After $10 \%$ of plastic strain, the $\{110\}\langle 001\rangle$ texture component disappears completely from the ODF and the Brass texture rotates $\sim 10^{\circ}$ about the sample's ND (from $\varphi_{1}=36^{\circ}$ to $\varphi_{1}=46^{\circ}$ ) giving a rise to the $\{110\}\langle 433\rangle$ texture component with an intensity of 7 (Fig. $8(\mathrm{c})$ ). Hence, the main texture component strengthens while the additional low intensity texture component disappears from the ODF, one can conclude that during deformation austenite grains with the $\{110\}\langle 001\rangle$ crystallographic orientation are the first that transform to martensite, because this component disappears from the ODF due to the transformation. Unfortunately, the small size of the austenite grains and the limited resolution of the EBSD system do not allow to find a direct confirmation of this assumption by measuring the orientation of the newly formed martensite simultaneously to that of the parent austenite.
Table 3. The crystallographic orientations of retained austenite in the TRIP-aided steel.

\begin{tabular}{|c|c|ccc|c|}
\hline TRIP-steel & Orientation & \multicolumn{3}{|c|}{ Euler angles } & ODF \\
& & $\varphi_{1}$ & $\Phi$ & $\varphi_{2}$ & Intensity \\
\hline \multirow{3}{*}{ As-received } & $\{110\}\langle 113\rangle$ & 65 & 90 & 45 & 3.2 \\
& $\{214\}\langle 121\rangle$ & 57 & 77 & 27 & 2.1 \\
& $\{113\}\langle 332\rangle$ & 90 & 25 & 45 & 1.3 \\
\hline \multirow{3}{*}{$10 \%$ deformed } & $\{110\}\langle 557\rangle$ & 45 & 90 & 45 & 3.0 \\
& $\{112\}\langle 111\rangle$ & 90 & 35 & 45 & 2.8 \\
& $\{214\}\langle 121\rangle$ & 57 & 77 & 27 & 2.9 \\
& $\{013\}\langle 100\rangle$ & 0 & 18 & 0 & 2.1 \\
\hline
\end{tabular}

There is a tendency of the retained austenite in the deformed TRIP-aided steel to develop a $\{112\}\langle 111\rangle$ texture component (Fig. 8(d)). Such a component is typical for the deformation of fcc metals ${ }^{16}$ ) and suggests the deformation of metastable retained austenite by dislocation slip prior to its strain-induced transformation to martensite.

\subsection{Evolution of Dislocation Substructure}

Typical TEM microstructure of the as-received TRIP steel shows that retained austenite and bainite exhibit irregular shape and are dispersed in ferrite matrix containing many dislocations (Fig. 9(a)). An important source of plastic strain accumulation in a deformed material is the volume change related to the $\gamma-\alpha^{\prime}$ strain induced by the phase transformation. The volume strain of the transforming $\gamma$ grains itself has to be accommodated by the surrounding matrix, and hence the dislocation density in the ferrite matrix increases substantially during transformation (Fig. 9(b)). Moreover, the retained austenite and ferritic bainite are neighbouring phases fulfilling special crystallographic orientation, which is preserved during materials defor mation (Fig. 9(c)). Zaefferer et al. ${ }^{17}$ ) show that the Kurdjumov-Sachs (KS) relationship of retained austenite and ferrite can be retained thanks to the development of 

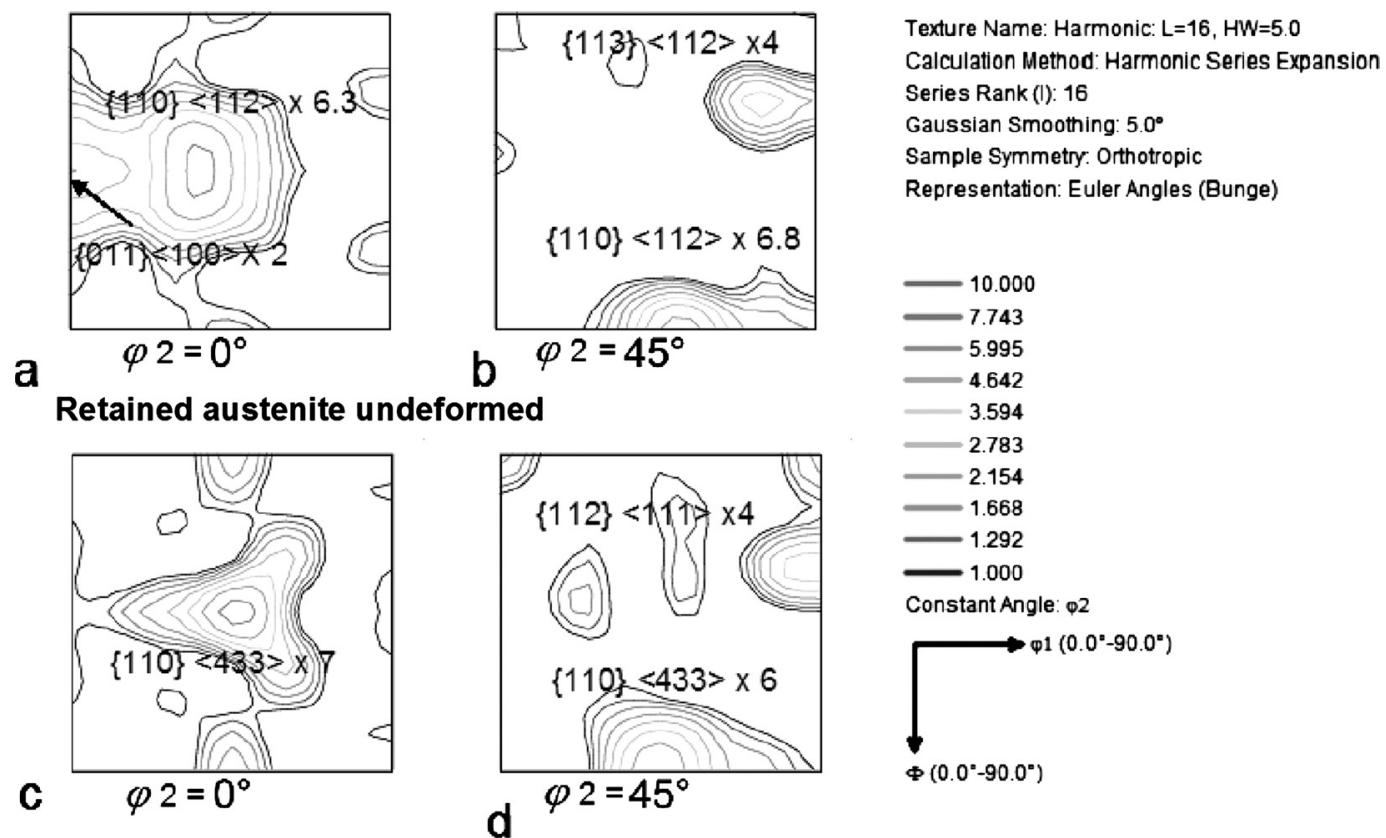

Retained austenite strained $10 \% \mathrm{RD}$

e

Fig. 8. Local textures of retained austenite before $(a, b)$ and after $10 \%$ pre-strain//RD (c, d); (e) iso-intensity levels (TRIP-steel).
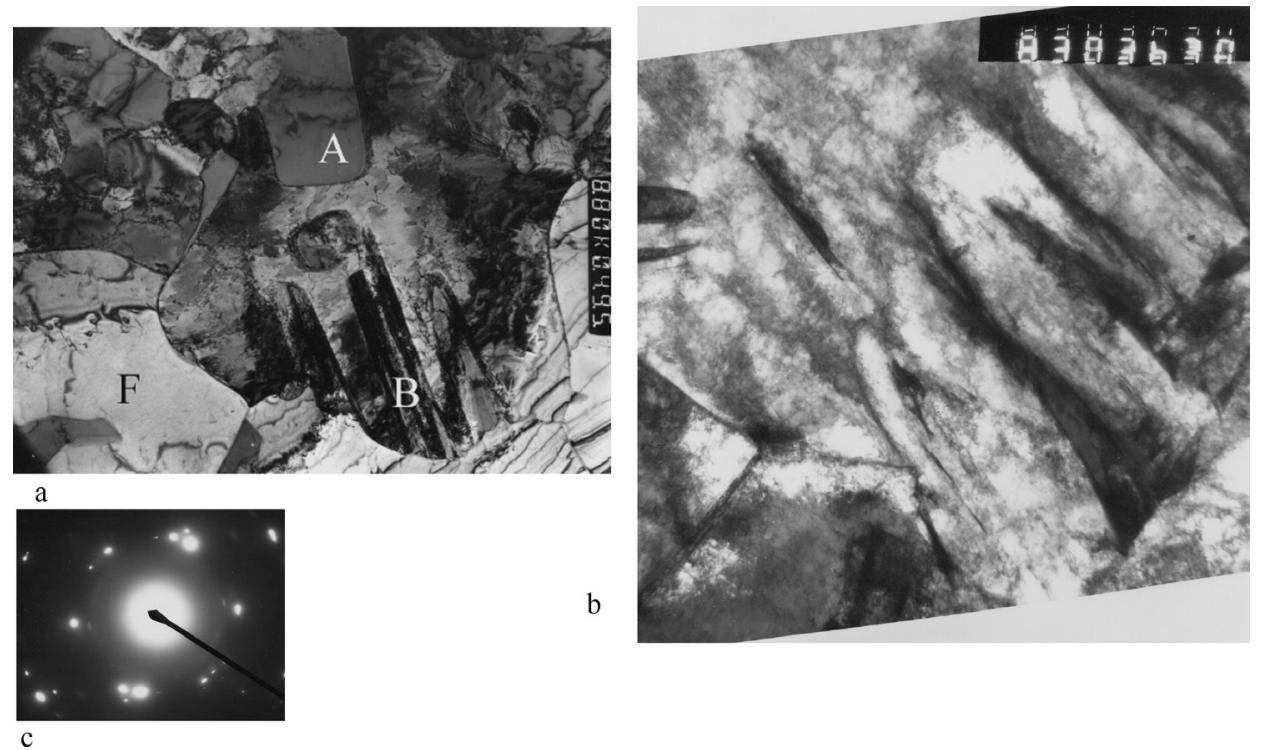

Fig. 9. Transmission electron micrographs of the TRIP-aided steel. (a) microstructure before deformation. F-ferrite, Aaustenite, B-laths of bainitic ferrite; (b) microstructure after $5 \%$ of plastic strain with corresponding selected area diffraction pattern (c).

strong orientation gradients in the neighbouring ferrite grains and they define this type of dislocated ferrite as "bainite". TEM observations of the deformed microstructure reveal that "geometrically necessary" dislocations are generated preferentially next to the phase boundaries which directly confirm the EBSD results shown in Fig. 5. These dislocations are mostly immobile and make a hard network together with the dispersed phases. The quantification based on the EBSD phase map (cf. Figs. 5(a), 5(c)) shows that the relative amount of the bcc phase increases with plastic strain (likewise the amount of retained austenite decreases from 10 to $4.5 \mathrm{vol} \%$ ). The ferrite grains are progressively consumed by a harder network consisting of dispersed phases: deformed ferrite, retained austenite and strain-in- duced martensite, so that the free path of dislocations in ferrite is decreasing with strain. This later observation is important for understanding the composite-like behaviour of TRIP-aided steels and the effect of strain-induced phase transformation on the structure refinement, distinguishing the flow behaviour of DP steels from that of the TRIP-aided steel.

\section{Conclusion}

The strain-induced transformation of retained austenite to martensite leads to localized deformation of ferrite close to the ferrite/martensite phase boundaries and the formation of a composite skeleton of several phases (bainite, retained 
austenite and martensite), clasping the ferrite grains, which thereby decrease in size. Ferrite and retained austenite deform simultaneously to minimize the local stresses at the phase boundaries, until the strain-induced martensitic transformation takes place. The composite-like strengthening behaviour in a TRIP-aided steel might be expressed by the decreasing free path of dislocations in ferrite due to the enlarging and thickening of the multiphase skeleton as plastic deformation progresses, without changing significantly the main texture components in the material.

\section{Acknowledgements}

The contributions of Prof. Wiktoria Ratuszek and Dr. Krzysztof Chrusciel (AGH University of Science and Technology, Krakow, Poland) to the X-ray measurements is gratefully acknowledged.

Dr. Roumen Petrov acknowledges the finical support of Nederland's Institute of Materials Research (NIMR) under the contract MC5.01109.

\section{REFERENCES}

1) W. Bleck: Proc. of Int. Conf. on TRIP-aided High Strength Ferrous Alloys, ed. by B. C. De Cooman, Steel GRIPS, Bad Harzburg, (2002), 13.

2) A. Wasilkowska, E. A Werner, M. Bartsch, S. Traint, A. Pichler and D. Huckert: Proc. of ISS Mechanical Working and Steel Processing Conf., eds. by F. Kongoli, B. G. Thomas, K. Sawamiphakdi, ISS and TMS, Warrendale, PA, (2003), 495.

3) A. Wasilkowska, W. Loos, E. A. Werner, S. Traint and A. Pichler: $J$.
Steel Related Mater. Steel Grips, 6 (2003), 440.

4) A. Wasilkowska, W. Loos, C. Krempaszky, E. A. Werner, R. Petrov, A. Pichler and S. Traint: Proc. of IVth Int. Cong. on Mechanical Engineering Technologies, Year XI, vol. 5/73, Varna, Bulgaria, (2004), 33.

5) G. Reisner, F. D. Fischer, Y. H. Wen and E. A. Werner: Metall. Mater. Trans., 30A, (1999), 2583.

6) H. Regle, N. Maruyama and N. Yoshinaga: Proc. of Int. Conf. on Advanced High Strength Sheet Steels for Automotive Applications, AIST, Warrendale, PA, (2004), 239.

7) L. Kestens, R. Petrov and Y. Houbaert: ISIJ Int., 43 (2003), 1444.

8) E. Girault, P. Jaque, Ph. Harlet, K. Mols, J. Van Humbeeck, E. Aernoudt and F. Delannay: Mater. Charact., 40 (1998), 111.

9) R. Petrov, L. Kestens, P. C. Zambrano, M. P. Guerrero, R. Colás and Y. Houbaert: ISIJ Int., 43 (2003), 378.

10) $\mathrm{TSL}^{\circledR}$ OIM Analysis for Windows: Version 4.3, User Guide, EDAX TSL $^{\circledR}$, TexSem Laboratories INC., Draper, UT, USA. (2004).

11) E. Wirthl, A. Pichler, R. Angerer, P. Stiaszny, K. Hauzenberger, T Y. Fitovets and M. Hackl: Proc. Int. Conf. on TRIP-aided High Strength Ferrous Alloys, ed. by B. C. De Cooman, Steel GRIPS, Bad Harzburg, (2002), 61.

12) Y. B. Park, D. N. Lee, and G. Gottstein: Acta Mater, 46 (1998), 3371.

13) H. J. Bunge: Methematical Methods for Texture Analyses, Akademie-verlag, Berlin, (1969).

14) P. Van Houtte: User manual, MTM-FHM Software, Ver. 2, ed. by MTM-KULeuven, (1995).

15) S. Traint, E. A.Werner, A. Pichler and P. Stiaszny: Proc. of 41st Mechanical Working and Steel Processing Conf., Vol. XXXVII, ISS, (1999), 25.

16) G. Wassermann and J. Grewen: Texture of Metallic Materials, Springer-Verlag, Berlin, (1962), 181.

17) S. Zaefferer, J. Ohlert, and W. Bleck: Acta Mater, 52 (2004), 2765. 